\title{
Adjustable suture strabismus surgery
}

\begin{abstract}
Surgical management of strabismus remains a challenge because surgical success rates, short-term and long-term, are not ideal. Adjustable suture strabismus surgery has been available for decades as a tool to potentially enhance the surgical outcomes. Intellectually, it seems logical that having a second chance to improve the outcome of a strabismus procedure should increase the overall success rate and reduce the reoperation rate. Yet, adjustable suture surgery has not gained universal acceptance, partly because Level 1 evidence of its advantages is lacking, and partly because the learning curve for accurate decision making during suture adjustment may span a decade or more. In this review we describe the indications, techniques, and published results of adjustable suture surgery. We will discuss the option of 'no adjustment' in cases with satisfactory alignment with emphasis on recent advances allowing for delayed adjustment. The use of adjustable sutures in special circumstances will also be reviewed. Consistently improved outcomes in the adjustable arm of nearly all retrospective studies support the advantage of the adjustable option, and strabismus surgeons are advised to become facile in the application of this approach. Eye (2011) 25, 1262-1276; doi:10.1038/eye.2011.167; published online 15 July 2011
\end{abstract}

Keywords: adjustable sutures; strabismus surgery; complex strabismus; pediatric strabismus; history of strabismus surgery

Hunter, Department of Ophthalmology, Children's Hospital Boston, Fegan 4, 300 Longwood Avenue, Boston, MA 02115, USA Tel: + 16173556766 ; Fax: + 16172490615 E-mail: david.hunter@ childrens.harvard.edu

Received: 2 February 2011 Accepted in revised form: 3 May 2011 Published online: 15 July 2011
BR Nihalani and DG Hunter

deviation will yield different results in different patients. This seems to be true both for 'simple' cases as well as for long-standing complex strabismus, reoperations, innervational abnormalities, restrictive myopathies, or following injuries to the eye.

The basic principle of any adjustable suture technique is to secure the extraocular muscle using a temporary or sliding knot. After the patient has recovered from anesthesia, the eye alignment is checked, and the length of suture between the attachment site and muscle is shortened or lengthened to fine-tune the alignment. The advantage of this technique is to reduce the need for reoperation by refining alignment in the early postoperative period before the muscle has firmly reattached to sclera.

In this article, we describe the basic approaches to adjustable suture surgery and review the important published results, with emphasis on recent advances. We will close with a discussion of special circumstances and perspectives on the future of adjustable suture strabismus surgery.

\section{History}

The first description of adjustable suture strabismus surgery was probably published by Bielschowsky ${ }^{1}$ in the German literature in 1907. He described the procedure as follows:

'After my suggestion, my highly honored chief Mr Geheimrat Sattler introduced a procedure at the University Eye Clinic Leipzig that has made the bad results we occasionally saw with muscle recessions disappear... A loose surgical loop is created, which initially leaves a gaping of the conjunctival wound margins. Then, strabismus and motility of the operated eye is checked, even on the operating table. Has the ocular motility in the area of the tenotomized muscle fallen below the allowed degree, one has to - without consideration of the fact that the reduction of the strabismic angle will again be in parts reverted-limit the effect. Of course this is also to be done if the surgery 
has overcorrected the strabismic angle; that is, in straight ahead gaze at distance there is a parallel or even divergent eye position.

The suture that connects the disinserted tendon with the two conjunctival wound margins allows for dosage and change of the immediate surgical effect, also during the two following days... Often the effect is bigger on postoperative day 1 than immediately after surgery and requires reduction. If the effect is smaller than intended, one loosens the suture or removes it on the evening of the surgical day. In general, a monocular dressing is sufficient, because the main concernavoidance of overcorrection-can be controlled with the adjustable suture. The suture can be removed on postoperative day 3 . Because the dressing limits lid excursions, there are hardly ever complaints of foreign body sensation.'

Bielschowsky $^{1}$

The first modern account of adjustable suture surgery was presented by Jampolsky in $1975 .{ }^{2,3}$ He described a two-stage approach, with the muscle secured to the eye with a bow tie knot, followed 4-24h later with adjustment of the sutures under topical anesthesia and conversion of the bow tie to a permanent knot. ${ }^{2}$

\section{Indications of adjustable suture strabismus surgery}

The indications for adjustable suture strabismus surgery are shown in Table $1 .^{2-14}$ Most authors agree that adjustable sutures are indicated when the surgical outcome is unpredictable. ${ }^{2,11}$ Other authors feel that these indications are too restrictive: Tripathi et $a l^{11}$ and others recommend adjustable suture strabismus surgery as 'the procedure of choice for all patients who are willing to cooperate.'

\section{Anesthetic and analgesic considerations}

Adjustable suture strabismus surgery is performed under general or local anesthesia per surgeon preference.

\section{General anesthesia}

General anesthesia allows for assessment of the position of the eyes under anesthesia, a valuable tool in surgical planning in some cases. ${ }^{15}$ It also allows for forced duction testing without concern for causing discomfort. Finally, general anesthesia avoids the need to wait for local anesthetic to wear off, allowing for earlier suture adjustment on the day of surgery (see 'Timing of Adjustment' below).

A recent study by Mizrak et $a l^{16}$ compared the effects of intravenous ketamine and propofol anesthesia in children undergoing strabismus surgery and found the infusion of ketamine to be more advantageous. The consumption of anesthetics and antiemetics, the
Table 1 Indications for adjustable suture strabismus surgery

Restrictive strabismus (Graves disease, scleral buckle, or anaesthetic myotoxicity)

Previous trauma or surgery

Slipped, lost, or disinserted muscles

Incomitant deviations (Duane syndrome, Moebius syndrome, myasthenia gravis or paralytic strabismus)

Combined horizontal, vertical, and torsional deviations

Any long-standing complex strabismus

'Any patient who can cooperate' (Tripathi et $a l^{11}$ )

incidence of oculocardiac reflex, recovery time, postoperative agitation score, face pain scale, and the Ramsay sedation score (during awakening and at postoperative 30th minute) were all significantly lower with ketamine anesthesia.

It is important to avoid older inhalational anesthestics, such as isoflurane and halothane, as they cause postoperative nausea and vomiting and more sedation, which make accurate postoperative examination nearly impossible. In addition, opioid analgesics/narcotics such as morphine should be avoided intra-operatively and postoperatively as they also increase the incidence of postoperative nausea and vomiting. ${ }^{17}$ There is evidence that intraoperative rectal acetaminophen and/or intravenous ketorolac can reduce postoperative discomfort without causing postoperative nausea and vomiting or sedation. ${ }^{18,19}$

Cogen $e t a l^{20}$ evaluated a general anesthetic technique that allowed immediate postoperative adjustment of sutures, thereby improving patient convenience and comfort while simplifying the logistics of the procedure. In this technique, comaintenance of anesthesia was accomplished using a stepped-down infusion of propofol with midazolam. Because propofol has a short half-life, patients were able to regain consciousness in $<5 \mathrm{~min}$ once the surgery was completed, eliminating extended time in the recovery room. Ward et $a l^{21}$ achieved total general anesthesia using infusion of propofol and used a short-acting muscle relaxant such as mivacuranium for accurate suture adjustment in the operating room immediately after completion of surgery. In our experience, patients are not sufficiently alert for intraoperative adjustment when any form of general anesthesia is used, and we wait a minimum of $1 \mathrm{~h}$ after surgery before performing the postoperative assessment.

\section{Local anesthesia}

Local anesthesia may be desirable or required in ambulatory settings that do not allow for general anesthesia and in patients in whom general anesthesia is not felt to be safe. When local anesthesia is used, short-acting agents are preferred. Sanders et $a l^{22}$ found peribulbar anesthesia with mixture of $2 \%$ mepivacaine 
hydrochloride and hyaluronidase to be a good choice for strabismus surgery. Szmyd et $a l^{23}$ recommended retrobulbar anesthesia in all adult patients undergoing monocular strabismus surgery. They found that the addition of hyaluronidase to $2 \%$ mepavicaine hydrochloride significantly decreased the duration of anesthetic and allowed for early recovery of extraocular muscle function. Brown et $a l^{24}$ recommend adjustment for 6 or more hours after peribulbar or retrobulbar injection, when $2 \%$ lidocaine with hyaluronidase was used for local anesthesia.

Sub-Tenon infusion is an efficient way to deliver anesthetic in strabismus surgery, because the conjunctiva must already be opened for surgery and the medication can be delivered directly to the desired quadrant. ${ }^{25}$ This method of administration also reduces the likelihood of anesthetic-induced strabismus that can occur when the muscle is inadvertently injected with local anesthetic agents using the retrobulbar or peribulbar approach. ${ }^{26}$ Bupivacaine (Marcaine) and other long-acting local anesthetics are not recommended for strabismus surgery if same-day suture adjustment is desired.

Topical anesthesia is another option for strabismus. Aziz et $a l^{27}$ performed a prospective, randomized study to evaluate the effect of deep topical fornix nerve block anesthesia in which a sponge soaked in $0.5 \%$ bupivacaine was placed deep in the conjunctival fornix for $15 \mathrm{~min}$, allowing for intraoperative suture adjustment. They found that no patient with this approach required conversion to general anesthesia, but more patients had discomfort during muscle traction than with peribulbar anesthesia. Hakim et al ${ }^{28}$ described single-stage adjustable suture surgery under augmented topical anesthesia using 2\% lidocaine gel in combination with intravenous nalbuphine.

When local anesthesia is required, we prefer subTenon administration under brief propofol sedation, using $4 \%$ lidocaine to reduce the volume of anesthetic in the retrobulbar space. In our experience, despite careful administration of what appears to be a complete retrobulbar block based on the pupillary response, many patients experience discomfort during muscle traction and conjunctival manipulation. Combining this discomfort with the inability to assess eye position under anesthesia and perform forced duction testing, we use local anesthesia only when general anesthesia is medically contraindicated.

\section{Surgical technique}

\section{Limbal vs fornix approach}

The limbal approach provides broad exposure during surgery and suture adjustment; however, it requires preplaced conjunctival closure sutures as it is otherwise difficult to cover the suture knot with the conjunctiva after the adjustment. The fornix approach includes a hidden incision underneath the eyelid, improving postoperative comfort, and producing excellent cosmetic results in most cases. Compared with a limbal approach, exposure of the surgical field is limited, which may increase the technical difficulty of surgery and suture adjustment. $^{29}$

Wright et $a l^{30}$ described the use of subconjunctival retraction suture for adjustable suture surgery with fornix approach. This suture retracts the conjunctiva, exposing the adjustable suture apparatus while simultaneously fixating the globe to facilitate adjustment.

Our preference is to use the fornix approach whenever possible, using the smallest possible incision to allow for more rapid rehabilitation of patients. Although we recommend the use of a traction suture for inexperienced adjustable suture surgeons, with experience this extra exposure is not needed during adjustment, and our preference is to perform the procedure without a traction suture.

\section{Muscle reattachment technique}

There are two basic approaches to muscle reattachment:

1. Bow tie technique (Figure 1a). After scleral passes, the sutures attached to the muscle pole sutures are tied to each other using a bow tie, as with a shoelace. During adjustment, the bow is untied, the muscle position adjusted, and the bow is retied. Once the desired alignment is obtained, the bow is cut and converted to a square knot.

2. Cinch or sliding noose technique (Figure $1 b$ ). The pole sutures are positioned to emerge from the scleral tunnels $<1 \mathrm{~mm}$ apart, with the ends secured to each other with an overhand knot. A noose is then created by tying a separate piece of suture around the pole sutures with a square knot. The ends of the noose suture are tied together to provide a 'bucket handle' for manipulation of the noose during adjustment. Once the desired alignment is obtained, most surgeons secure the pole sutures to each other with a permanent square knot and trim the noose.

There are minor variations in the technique of adjustable sutures used by various surgeons; ${ }^{4-13}$ however, the principles of the technique remain constant.

\section{Timing of adjustment}

Most surgeons perform the suture adjustment within the first $24 \mathrm{~h}$ after surgery. Spierer ${ }^{31}$ found that muscle adjustments performed 8 or $24 \mathrm{~h}$ after horizontal strabismus surgery had similar outcomes. Velez et $a l^{32}$ 

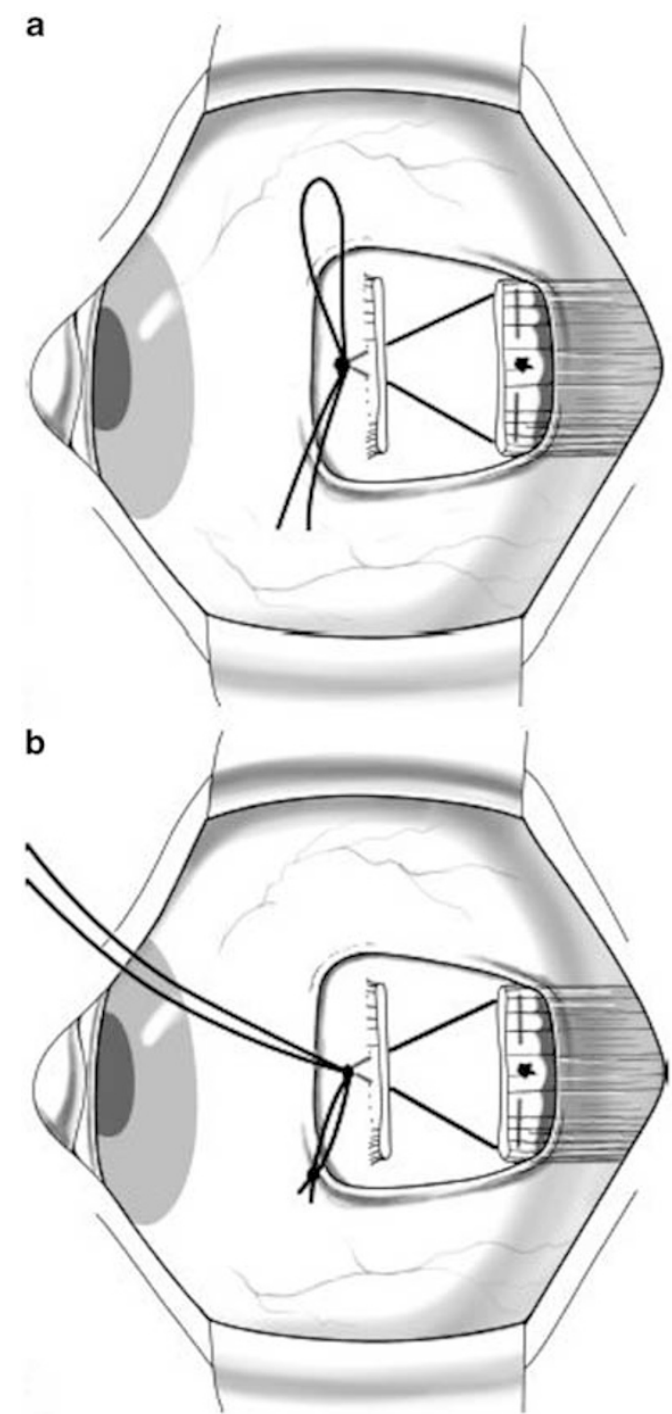

Figure 1 Basic adjustable suture techniques. (a) Bow tie technique: the sutures are tied together in a single-loop bow tie similar to a shoelace. (b) Sliding noose technique: a noose is created by tying a separate piece of suture around the scleral sutures. Reproduced with permission from Hunter et al. ${ }^{84}$

also found no difference between performing adjustment on the same day of surgery or the next day with respect to pain before, during, or after adjustment, to the ease of performing the adjustment, and to the final alignment. We generally perform suture adjustment $1-2 \mathrm{~h}$ after surgery if the patient is sufficiently alert, ${ }^{33}$ enhancing alertness by asking patients to sit up on the edge of the bed without support and with legs dangling.

As noted in the 'Anesthetic and Analgesic Considerations' section above, others have proposed earlier - even intra-operative - suture adjustment. Yi et $a l^{34}$ found that intra-operative adjustment was useful for comitant horizontal strabismus surgery and provided the opportunity to avoid a large overcorrection, especially in cases of moderate angle horizontal muscle surgery. Cogen et $a l^{20}$ stated that intra-operative adjustment offers many practical benefits to both the surgeon and patient, such as sterile conditions and availability of all ancillary personnel and instruments if needed. In addition, the cost of extended time for patients and staff in the recovery room is eliminated. In contrast, Bleik and Karam ${ }^{35}$ cautioned against immediate postoperative adjustment. They reported that the immediate postoperative ocular alignment, measured just 7-22 min after surgery, was significantly different from the alignment $24 \mathrm{~h}$ later. They recommended that this early drift should be taken into account if adjustment in the immediate postoperative period is required; however, the authors did not measure alignment $1 \mathrm{~h}$ after surgery, which is when we typically perform our assessment.

Although some surgeons are working toward validating earlier adjustment, others have described techniques that extend the time for suture adjustment up to 14 days after surgery. ${ }^{36-38}$ This is covered in more detail in the 'Optional Suture Adjustment' section below.

\section{Results of adjustable suture strabismus surgery}

A number of studies have been published over years that describe the results of adjustable suture strabismus surgery in adults. ${ }^{4-11}$ Some studies report no advantage of adjustable sutures. Park et $a l^{12}$ found that strabismus surgery with adjustable sutures $(n=20)$ did not show significantly better results than surgery without adjustable sutures $(n=34)$ in the treatment of sensory exotropia. Bishop and Doran ${ }^{13}$ found an equally high success rate in adjustable and non-adjustable suture groups ( $81 \%$ vs $88 \%$ ) in their retrospective case-matched study of 52 cases. Both groups concluded that a much larger study will be required to provide sufficient statistical power to detect a significant difference in results. Most published studies show an advantage of adjustable suture surgery, though few have provided compelling statistical support. Table 2 summarizes the results of the 18 major adjustable suture strabismus surgery studies published since 1972.

Despite continued and widespread skepticism about the effect of adjustable suture surgery, there are no prospective, randomized, controlled trials addressing this topic. A 2005 Cochrane review ${ }^{39}$ summarized all $^{2}$ available literature and found that the studies that directly compared adjustable and non-adjustable suture techniques were nonrandomized, few in number, and mainly retrospective. Different studies were difficult to compare as a result of marked clinical heterogeneity. Thus reliable conclusions could not be drawn concerning 


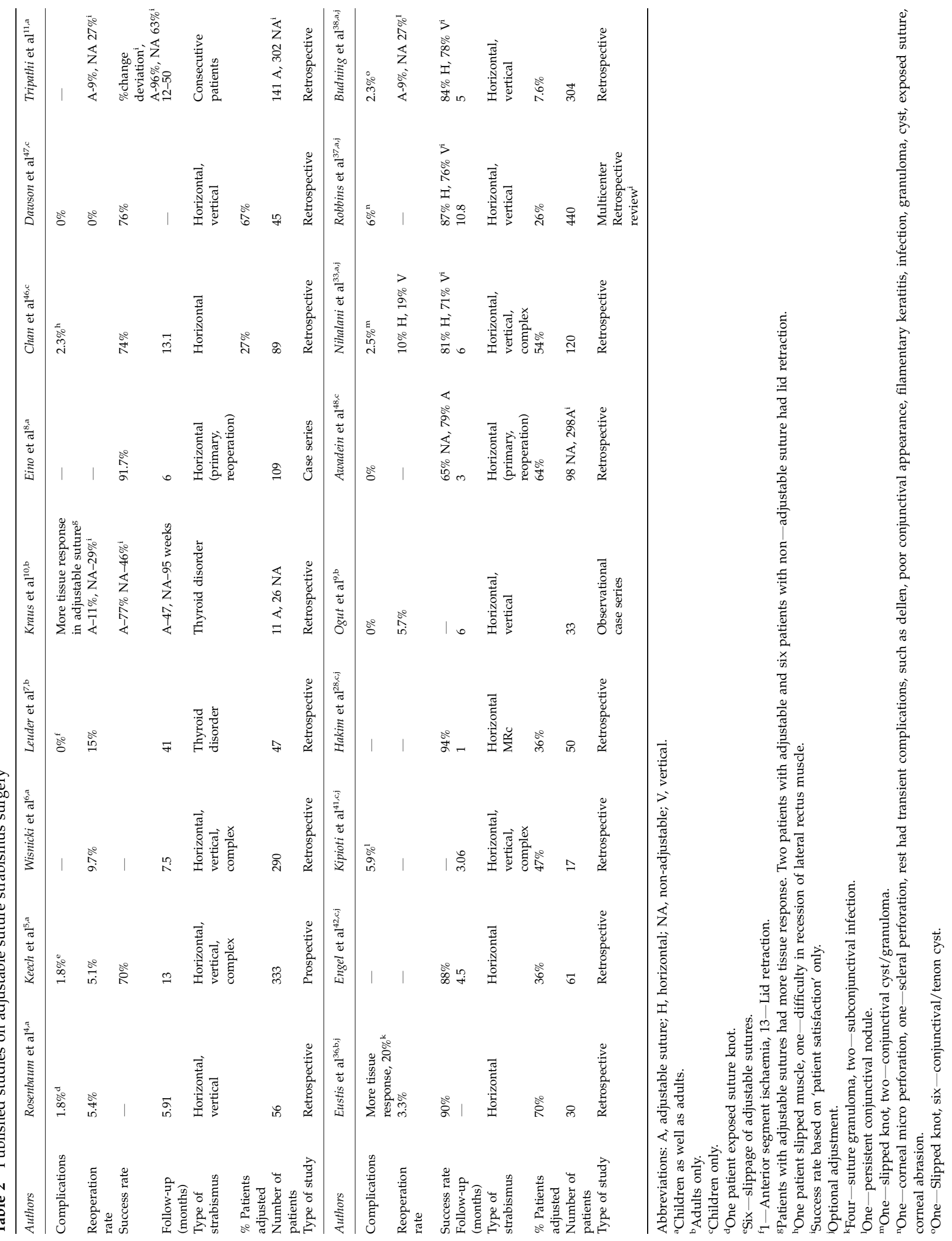


the advantages of adjustable suture surgery in general or of any approach in particular.

\section{Optional suture adjustment}

In conventional adjustable suture surgery, a second stage is required to tie and trim the suture ends whether or not patients require adjustment. Saunders and $\mathrm{O}^{\prime} \mathrm{Neil}^{40}$ described a technique in which a bow-tie adjustable suture was left untied in 22 patients (52\%). There was no incidence of muscle slippage in their study. With these encouraging results, various modifications of conventional adjustable suture strabismus surgery have been described. The results of these studies are included in Table 2. Kipioti et $a l^{41}$ left the loop of bow tie in the quadrant opposite that where the conjunctiva was likely to be reopened should the adjustment be required. The sutures were left $\sim 5-6 \mathrm{~mm}$ long to allow adjustment if necessary, and the loose ends were tucked under the conjunctiva. The conjunctival flaps were closed to completely cover the muscle and suture loops in a way similar to conventional strabismus surgery. Eustis et $a l^{36}$ described an absorbable subconjunctival adjustable suture in which the pole sutures were tied with a bow tie and the sutures were left 5-7 mm long for suture adjustment. A traction suture was placed through the sclera just anterior to the top edge of the insertion. When the traction suture was retracted, the insertional stump and Vicryl sutures were exposed. A double knot was placed 5-7 mm distally along the traction suture, and the suture was positioned in such a way that the knot was easily visualized through the fornix incision, which was closed after the sutures were tucked into the subconjunctival space. They performed delayed adjustment in 11 patients $(52.4 \%)$ in the office up to 4 days after surgery. Engel et $a l^{42}$ used a sliding noose adjustable suture technique, leaving $6-7 \mathrm{~mm}$ of pole suture material extending beyond the noose to allow for increased recession. A separate partial thickness scleral pass was then made in the area of fornix incision to hold the pole suture extensions in place, and the pole sutures were then tied to each other to further reduce the likelihood of a slipped muscle. The conjunctiva was closed to bury the sutures, and re-opened if suture adjustment was required.

Nyugen et $a l^{43}$ described the 'releasable conjunctival suture' in which the muscle and conjunctival sutures were tied in a bow and tucked under the conjunctiva. Hakim et $a l^{44}$ described a releasable adjustable suture technique for medial rectus recessions, which allowed $2 \mathrm{~mm}$ or more of adjustment when the suture was released. Coats ${ }^{45}$ described a ripcord adjustable suture technique, which allowed for a one time, single-stage adjustment of recessed or resected muscles in a

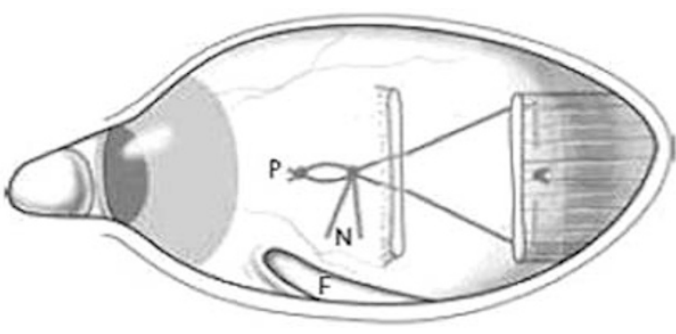

Figure 2 Short tag noose technique showing the fornix incision $(\mathrm{F})$, trimmed pole sutures $(\mathrm{P})$, and trimmed noose $(\mathrm{N})$ buried under the conjunctiva. Reproduced with permission from Hunter et al..$^{84}$

predetermined, all-or-nothing step by releasing an 'adjunct suture' (separate from the pole sutures) to increase the recession (or decrease the resection) if required. The disadvantage of the techniques of Hakim et al and Coats is that they do not allow titration of postoperative adjustment.

We described the 'short tag noose' technique, in which standard sliding noose adjustable suture surgery was performed, but the pole sutures and noose were trimmed (to 'short tags') and tucked under conjunctiva. ${ }^{33}$ An overhand knot was placed $\sim 3 \mathrm{~mm}$ away from the suture exit site, allowing for an additional $3 \mathrm{~mm}$ recession (though we now leave the pole sutures $5 \mathrm{~mm}$ long to allow for a larger recession and to facilitate placement of the sutures under conjunctiva as well as retrieval). The noose sutures were trimmed to $<5 \mathrm{~mm}$ (Figure 2) and left without an overhand knot to differentiate from the pole sutures (though we now leave the noose sutures $5 \mathrm{~mm}$, placing an overhand knot on both the pole sutures and the noose, leaving longer 'whiskers' on the noose to distinguish it from the pole sutures). We performed delayed adjustment 2 or more days after surgery in 15\% of procedures. The conjunctival incision had typically self-sealed when the adjustment was performed $>24 \mathrm{~h}$ after surgery, but it was easily opened with a forceps. A muscle hook was used to gently separate the muscle from sclera if the muscle was firmly adherent to the sclera.

Robbins et ll $^{37}$ described a 'closed conjunctival delayed adjustable suture technique' that is similar to the short tag noose technique. In this approach, performed with different variations by surgeons at several centers, either a sliding noose or bow tie knot was used to secure the pole sutures. An absorbable traction suture was placed adjacent to the original insertion site. All sutures were tucked under the conjunctiva, which was re-approximated with sutures. In their study, the mean time of adjustment was 2.5 days (median 1 day; range 0-14 days). No surgeon in this study reported difficulty with scleral adhesions limiting the ability to perform the late adjustment. In our experience, these adhesions are 
uniformly present and must be broken to allow for adjustment by briefly passing a small hook under the muscle. Budning et $a l^{38}$ described a 'short adjustable suture' which was also similar to the short tag noose technique. They adjusted $47.4 \%$ (9/19) patients $>1$ day after surgery (range: 1-6 days). None of these studies showed a statistical advantage to the delayed adjustment, but the authors advocated this approach because of the improved flexibility for performing, if necessary, an adjustment after the angle of strabismus had stabilized.

\section{Adjustable sutures in children}

In his original description of adjustable sutures, Bielshowsky ${ }^{1}$ stated that the technique was 'namely important for children, who underwent surgery under general anesthesia.' Despite his recommendations over 100 years ago, there are very few reports today on the use of adjustable sutures in children. This is most likely because of the difficulty obtaining the cooperation of a child, both for postoperative assessment and for the actual adjustment. In young children, the use of the adjustable suture technique often requires a second stage of anesthesia for suture adjustment. The techniques that utilize optional adjustment therefore seem logical for use in children. The results of both pediatric and adult studies using mandatory or optional adjustment are combined in Table 2.

Chan et $\mathrm{l}^{46}$ studied adjustable sutures in children older than 7 years (mean, 11.7 years, range: 7-15 years) and performed adjustment on the morning after surgery under topical tetracaine. They did not perform sedated suture adjustments. Dawson et $a l^{47}$ included children aged 10-15 years (mean, 13 years). They left the suture ends long at the end of surgery; hence all patients required suture manipulation, even if only to tie and trim the suture ends. Adjustment was performed under topical anesthesia. Eustis et $a l^{36}$ performed most adjustments under topical anesthesia and injected subconjuntival lidocaine in children who felt persistent pain. They did not provide the age of their patients in their report. Engel et $a l^{42}$ adjusted the sutures in children (aged 12 months-14 years; median, 5.1 years) 4-7 h after the primary surgery. The intravenous lines from surgery were left in place and patients were allowed clear liquids until about $2 \mathrm{~h}$ before adjustment. Adjustment was performed in the operating room under intravenous propofol sedation or laryngeal mask anesthesia. Hakim et $a l^{44}$ left the releasable suture in place if the alignment was found to be satisfactory on the first postoperative day, but if adjustment was required, lidocaine hydrochloride $2 \%$ jelly was applied to eye for $5 \mathrm{~min}$ and adjustment was performed without sedation. Children aged 10 months to 7 years (mean, 2.8 years) were included in their study. Awadein et $a l^{48}$ did not use an optional adjustment technique; they used topical proparacaine for the adjustment if children were able to cooperate, or intravenous propofol, $3 \pm 1 \mathrm{mg} / \mathrm{kg}$, for those who could not. The mean age in the adjustable group was $4.7 \pm 2.5$ years (range, 6 months -10 years). The results obtained using adjustable sutures in children were similar to those obtained by other authors in adults (Table 2) and better than the results obtained in their own non-adjustable historical pediatric control group.

Adjustable suture surgery is thus feasible in children, and appears (in nonrandomized, retrospective studies) to show an advantage over non-adjustable techniques. We routinely use the approach in children who meet the criteria outlined in Table 1. When planning adjustable suture surgery in children, we inform the anesthesia and postoperative care staff in advance of any planned pediatric adjustable suture case and keep children NPO after surgery for $1-2 \mathrm{~h}$ until the postoperative assessment is complete. If suture adjustment is required, we perform it at the bedside in the postanesthesia care unit (recovery room) to avoid the complexities and expense of returning to the operating room.

\section{Special circumstances}

\section{Adjustable superior oblique (SO) surgery}

The adjustable SO suture spacer, first described by Suh et $a l,{ }^{49}$ is a modification of Knapp's 'chicken suture' ${ }^{50}$ and Wright's superior oblique 'tendon expander' techniques. ${ }^{51}$ The procedure allows for partial, reversible, and intra-operatively adjustable SO weakening using a non-absorbable suture (rather than a fixed silicone band used for the tendon expander) to separate the cut ends of the SO tendon (Figure 3). The suture allows the separation to be adjusted in a graded manner (rather than the uncontrolled weakening obtained using the 'chicken' suture), and the tension can be refined intraoperatively after performing the exaggerated traction test and fundus torsion assessment. Long-term results of this technique in patients with Brown syndrome showed that the abnormal head posture improved from $13^{\circ}$ to $0.4^{\circ}$ by improvement of vertical strabismus in primary position from $-10^{\Delta}$ to $2.8^{\Delta}$ and in the affected field of gaze from $-20^{\Delta}$ to $-1.5^{\Delta}$ while avoiding overcorrection in contralateral gaze. ${ }^{52}$ Thuangtong and Isenberg ${ }^{53}$ described a horizontal mattress technique to further facilitate intra-operative adjustment.

Although the suture spacer can only be adjusted intraoperatively, others have developed techniques allowing for postoperative adjustment of the $\mathrm{SO}$ tendon 

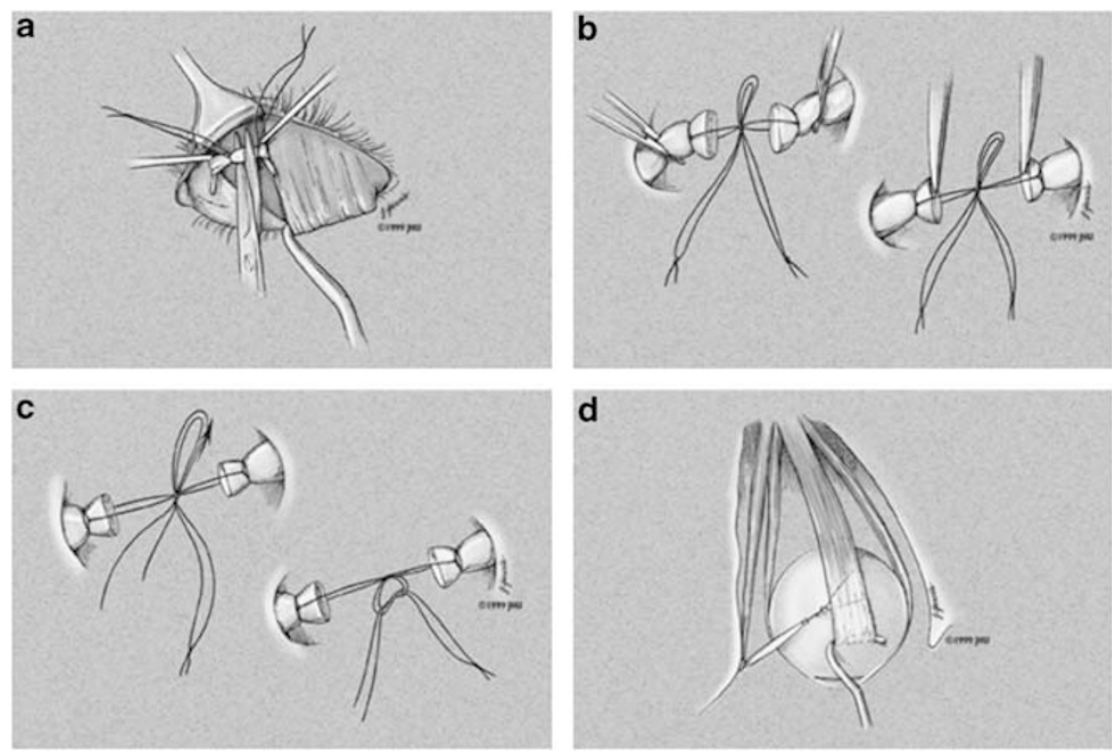

Figure 3 Surgical technique of adjustable SO suture spacer. (a) Exposure of the SO tendon and placement of sutures. (b) Sutures tied, leaving a gap of 2-8 mm. (c) The slipknot is converted into a square knot by cutting one of the pairs of sutures and passing this pair through the knot. The sutures are then secured with a permanent square knot. (d) Final position of SO tendon, with suture spacer in place. Reproduced with permission from Suh et al. ${ }^{49}$

weakening. Goldenberg-Cohen $e t a l^{54}$ described a surgical procedure in which a permanent suture was used to separate the two cut ends of the tendon, with a sliding noose for adjustment. This noose could be accessed by having the patient to look up or straight ahead during adjustment at the bedside.

The Harada-Ito procedure has been used for years to improve the torsional deviation in patients with SO palsy without substantial vertical deviation, but accurate guidelines for how much the $\mathrm{SO}$ muscle should be tightened are not available. Metz and Lerner ${ }^{55}$ performed an adjustable Harada-Ito procedure in four patients with SO palsy. In their technique, 6-0 polyglactin 910 suture was sewn through the anterior fibers of $\mathrm{SO}$ tendon, which were then severed from the globe. The anterior half of the tendon was reattached to the eye $4 \mathrm{~mm}$ anterior and $6 \mathrm{~mm}$ temporal to the original insertion (Figure 4). A sliding noose of absorbable suture was then secured anterior to the $\mathrm{SO}$ suture attachment. The conjunctiva was closed and the long ends of the suture were extended $5 \mathrm{~mm}$ to allow for adjustment (and tucked into the cul-de-sac). During adjustment, the noose was repositioned as required. On subsequent examinations up to 20 months postoperatively there was no evidence of subjective cyclotorsion or iatrogenic Brown syndrome. Nishimura and Rosenbaum ${ }^{56}$ described an adjustable Harada-Ito procedure that used a split tendon approach and thus did not require detachment of the $\mathrm{SO}$ tendon fibers. They performed adjustment 1 day after surgery, adjusting for zero torsion on double Maddox rod testing in primary position. The authors described excellent short-term results, but with partial regression of the correction toward excyclotorsion occurring 2-12 months postoperatively. They therefore recommended adjustment toward an initial overcorrection. Ameri et $a l^{57}$ performed a similar procedure in just two patients, but with intraoperative adjustment. The amount of tuck was adjusted until, on torsion testing using indirect ophthalmoscopy, the fovea was at the level of superior one-third of the disc ( +3 intorsion). A double Maddox rod test was used to evaluate subjective torsion intraoperatively in one case. Neither patient had regression toward excyclotorsion during 18 months of follow-up.

\section{Adjustable inferior oblique surgery}

Kumar $e t l^{58}$ described a hang-back recession of inferior oblique muscle in V-pattern strabismus with

overelevation in adduction. In this technique, a doublearmed 6-0 polyglactin 910 suture was passed through the inferior oblique muscle $5 \mathrm{~mm}$ from the insertion, secured with locking bites on both ends, and then passed through the muscle a second time just $3 \mathrm{~mm}$ from the insertion without tying the proximal end. This formed a loop between the proximal and distal muscle, and the muscle was cut between the sutures. The amount of recession ( $8 \mathrm{~mm}$ for mild cases and $12 \mathrm{~mm}$ for severe cases) was determined using the length of suture between cut ends, and the proximal ends of the suture were tied. The muscle was allowed to retract into its sheath and was expected to stay recessed, preserving the normal course 

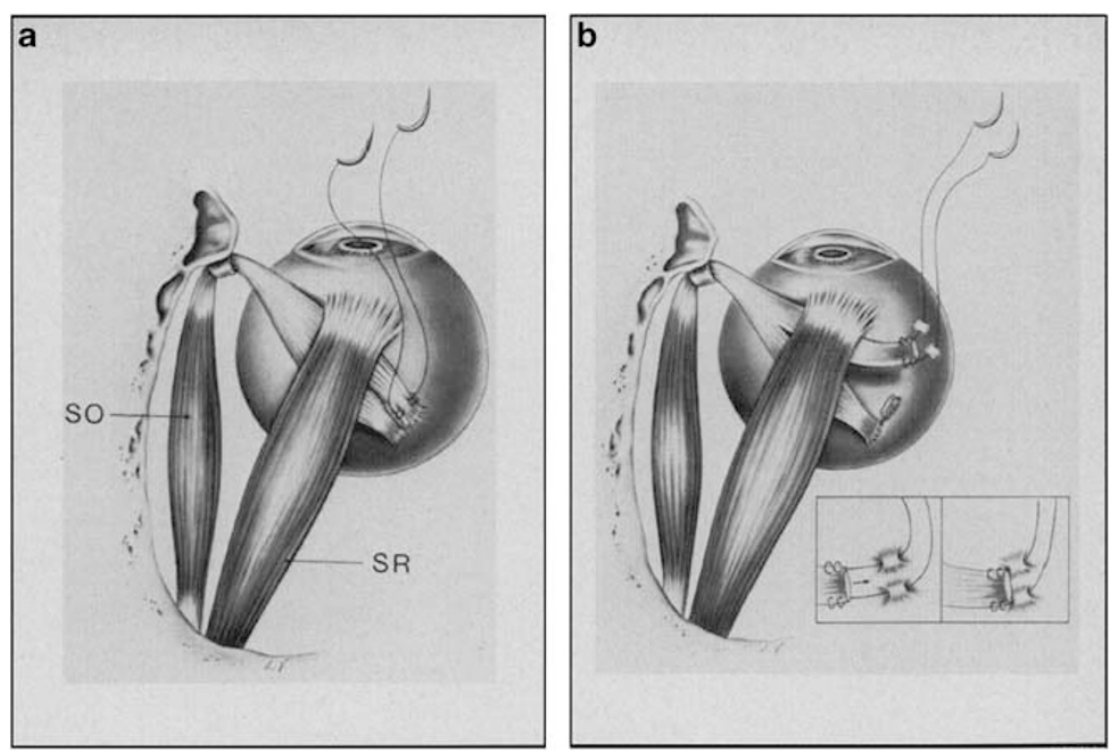

Figure 4 (a) Insertion of SO tendon is exposed lateral to superior rectus (SR) muscle. SO tendon is split about $10 \mathrm{~mm}$ back, and suture is sewn through anterior fibers of tendon just behind insertion. (b) Anterior fibers of SO tendon have been disinserted and sutures sewn through partial thickness sclera in more anterior and lateral position. Postoperatively, suture can be allowed to slide back or be pulled forward (see inset boxes) to either weaken or strengthen effect of partial SO tendon advancement. Reproduced with permission from Metz and Lerner. ${ }^{55}$

of the muscle. Although this technique provides a theoretical opportunity for suture adjustment, no adjustment was performed in any patient.

\section{Adjustable posterior fixation sutures}

The posterior fixation suture (Faden operation) is used in patients with incomitant strabismus to limit movement of the less severely affected eye without affecting primary position alignment. Although the standard posterior fixation suture involves a permanent suture that is not adjustable, Scott ${ }^{59}$ suggested a modification to the procedure that could preserve the option of adjustment. In his approach, a large resection of the muscle is followed by even larger recession of the same muscle using an adjustable technique. This moves the effective attachment site of the muscle back to the equator, producing a mechanical effect similar to that of the posterior fixation suture. Dawson et $a l^{60}$ and Thacker et $a l^{61}$ found this technique to be helpful for the treatment of incomitant strabismus in a subset of patients who were asymptomatic in primary position but diplopic in secondary functional gaze positions.

Sarnicola ${ }^{62}$ described a method of crossing the posterior fixation sutures to combine the procedure with a standard adjustable recession. In this technique a 5-0 polyester retro-equatorial suture was tied across the muscle without passing through its body. A removable suture fragment was passed through the retroequatorial fixation suture to offer a counteracting force during the adjustment, allowing an easier increase in recession. They described satisfactory results in 13 patients; 8 with exotropia $>60^{\Delta}$ prism diopters, 4 with unilateral DVD $>40^{\Delta}$, and 1 with nystagmus blockage and esotropia. More recently, Holmes et al ${ }^{63}$ described a method of placing a longitudinal split in the lateral rectus muscle at the point of attachment of the two posterior fixation sutures, thus allowing for adjustable recession of the lateral rectus muscle (Figure 5). Three patients with incomitant exodeviations were treated; a -1 limitation of abduction with improvement in the incomitance was achieved in all three patients.

\section{Semiadjustable sutures}

Sprunger and Helveston ${ }^{64}$ recognized that the inferior rectus (IR) muscle is uniquely prone to overcorrection after recession, with other rectus muscles showing a much lower propensity for late overcorrection. The reported incidence is $7-41 \%$. The problem may be more likely to occur after adjustable recession, ${ }^{65}$ and it may occur in the presence or absence of thyroid eye disease. ${ }^{66}$ This increased tendency of the IR muscle to slip may be related to the gravitational pull of the muscle away from the eye during healing. Kushner ${ }^{67}$ described a 'semiadjustable' technique in an effort to secure the IR muscle more firmly to the globe (and against gravity), thus reducing the incidence of muscle slippage while preserving the potential for adjustment. The process involves attaching the corners of the IR muscle firmly to 

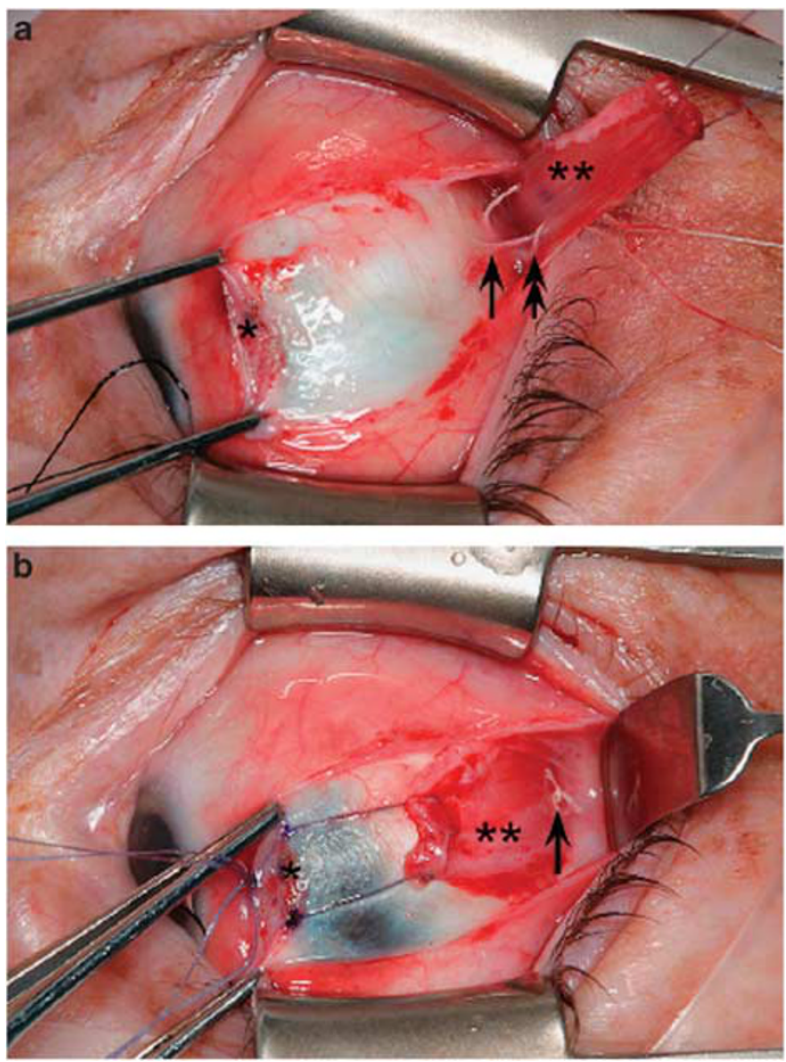

Figure 5 (a) Lateral rectus posterior fixation: $3 \mathrm{~mm}$ scleral bite (arrow) taken $18 \mathrm{~mm}$ from original insertion. Each arm of a double-armed Mersilene suture is passed through the muscle belly, one-third muscle width from superior and inferior edge (double arrow). (b) The Mersilene suture is then tied over the middle-third of the muscle (arrow). *Indicates the original insertion of the lateral rectus muscle; ${ }^{* *}$ indicates lateral rectus muscle. This case shows a simultaneous recession of $7 \mathrm{~mm}$ on an adjustable suture. Reproduced with permission from Holmes et $a .^{63}$

sclera with fixed sutures while placing the center of the muscle on an adjustable suture (Figure 6). A trade-off of this procedure is that it limits the capability to increase the amount of recession at the time of adjustment. By targeting an initial overcorrection, this downside is limited. Shokida et al ${ }^{68}$ introduced a variation by adding a non-absorbable 'safety stitch' to reduce late overcorrection. A non-absorbable suture was placed in the medial edge of the IR tendon and fixed at the scleral insertion of the muscle. After the adjustment the safety stitch was fastened with a knot. With this technique the authors achieved successful outcome in 10 out of 11 surgeries, with an average follow-up of 1 year.

\section{Lid retraction and inferior rectus recession}

Retraction of the lower eyelid occurs frequently after large IR recession despite meticulous dissection of the

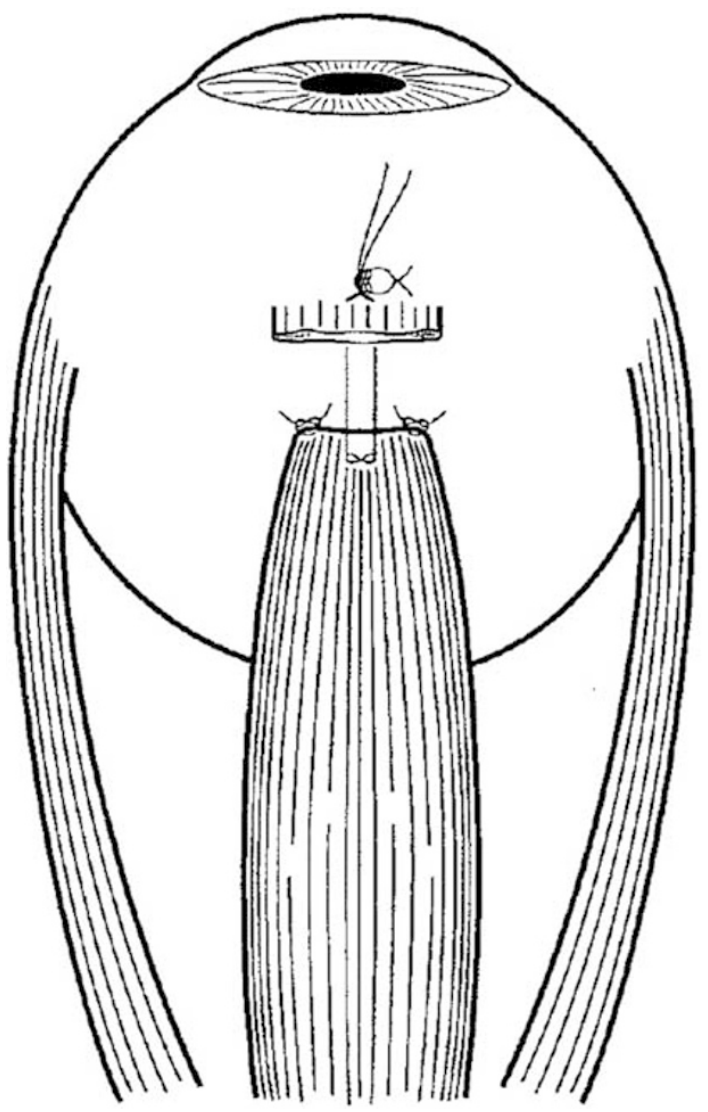

Figure 6 Semiadjustable sutures showing that the corners of IR muscle are sutured firmly to the sclera and the center of the muscle is placed on an adjustable suture. Reproduced with permission from Kushner. ${ }^{67}$

connective tissues around the muscle. Kushner ${ }^{69}$ described advancement of the capsulopalpebral head to minimize postoperative lower lid retraction. In this technique, a double-armed 6-0 polyglactin 910 suture was placed in a horizontal mattress fashion through the capsulopalpebral head close to its attachment to the IR, about $14-15 \mathrm{~mm}$ from the limbus. After the muscle was recessed, (with adjustable or non-adjustable technique) the capsulopalpebral head was reattached to the globe with a horizontal mattress suture at the original distance from the limbus. In cases where the recession exceeded $7-8 \mathrm{~mm}$, the technique was modified to place the suture through the IR muscle $\sim 1 \mathrm{~mm}$ posterior to its anterior edge so that it would not interfere with suture adjustment. In a prospective, randomized, masked clinical trial of 38 patients, Kushner reported that the mean postoperative lower eyelid retraction was significantly lower in patients treated with this method ( $0.7 \pm 0.8$ vs $1.3 \pm 0.8 \mathrm{~mm}$ in controls.)

Pachecho et $a l^{70}$ described a technique that involved an adjustable suspension of the lower eyelid retractors from the inferior rectus insertion at the time of strabismus 

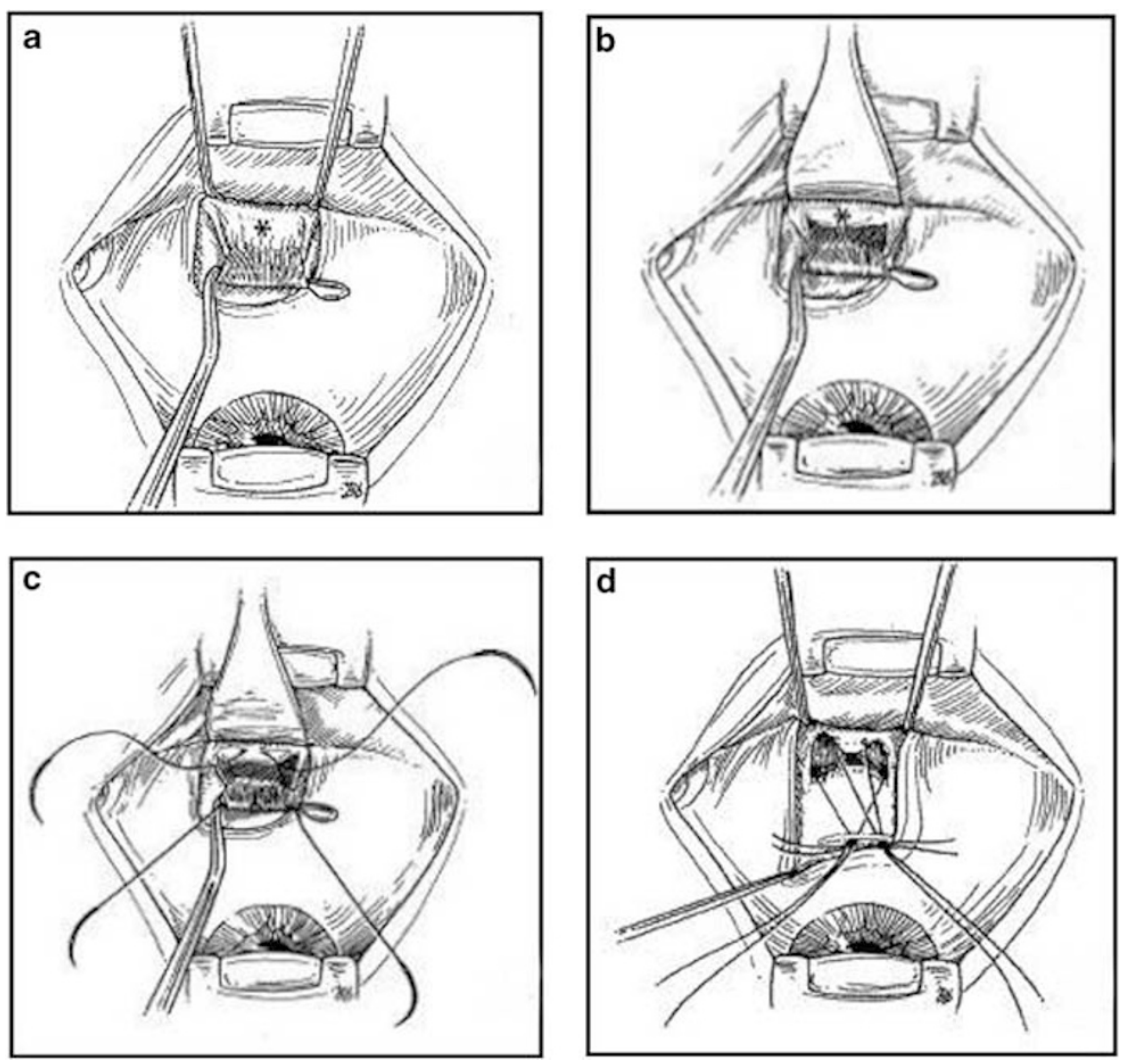

Figure 7 (a) Surgeon's view of the IR muscle. Note the capsulopalpebral head (CPH) of the IR $\left(^{*}\right)$ arising from the muscle $4.0-5.0 \mathrm{~mm}$ from its insertion. (b) Appearance of the $\mathrm{CPH}\left({ }^{*}\right)$ and capsule of the IR muscle following dissection of check ligaments and other fibrous attachments from the muscle. (c) Double-armed 6-0 polyglactin 910 sutures on the IR muscle and on the cut end of the CPH of the muscle. (d) Adjustable suspension of the lower eyelid retractors from the original IR insertion temporal to the muscle's adjustable suture. Reproduced with permission from Pacheco et al. ${ }^{70}$

surgery (Figure 7). The lid position was then adjusted separately from the alignment at the time of suture adjustment. With $2 \frac{1}{2}$ months follow-up, the authors found no lid retraction in six patients treated with the adjustable lid suspension compared with significant lid retraction in nine controls undergoing inferior rectus recession alone.

\section{Postoperative drift}

One assumption of adjustable suture surgery is that the eye position at the end of suture adjustment will not change as the eye heals, or that the amount of change will be reduced, or it will at least change in a more predictable manner. Therefore, it is important to be aware that it is still not possible to fully predict the extent of postoperative drift that will occur after suture adjustment. Eino and $\mathrm{Kraft}^{8}$ found that both esotropia and exotropia groups had equal tendency to drift toward either under- or overcorrection over 6-8 months. Isenberg et $\mathrm{al}^{71}$ found that most exotropia patients developed a general drift toward undercorrection. In our short tag noose series, ${ }^{33}$ we observed that postoperative drift was toward undercorrection in patients with esotropia, exotropia, and vertical deviation. Mean vertical drift toward undercorrection was less than mean horizontal drift. Although there is a general tendency toward undercorrection, we intentionally adjust for overcorrection only in exotropia patients. The exact modification of the target alignment for our patients who undergo late suture adjustment continues to evolve, but in general we try to anticipate (or adjust for) orthotropia $>2$ days after surgery.

\section{Complications}

Any complication that may occur as a result of strabismus surgery may also occur with adjustable suture surgery. Complications unique to the adjustable suture technique include vagal reactions during suture adjustment, increased postoperative inflammation, exposed sutures, and slipped adjustable suture knot.

Intra-adjustment complications include nausea, vomiting, and ocular pain. An oculocardiac reflex and 
possible bradycardia may be associated with muscle manipulations, thus some patients may experience syncope, lightheadedness, diaphoresis, or sense of temperature change. ${ }^{72,73}$ This has been more likely to occur, in our experience, during late suture adjustments. The complication may be minimized by infusing subconjunctival lidocaine around the adjustable sutures at the beginning of the late adjustment and by making slow, deliberate movements, keeping the patient informed about what to expect at every step of the procedure. It is important to communicate regularly with the patient so that the vagal episode can be recognized early, when the patient tends to become quiet or describes a 'funny' feeling, so that the procedure can be suspended and the patient given supportive care while the episode passes. Once the episode has passed, it is normally possible to resume the adjustment without further incident.

Eustis $e t a l^{36}$ found a more robust tissue response to surgery in patients with adjustable sutures, with 4 of 30 (13\%) patients developing suture granuloma and 2 (7\%) patients with a sub-conjunctival infection. Mocan and Azar $^{74}$ reported four patients who developed severe conjunctival dehiscence, requiring amniotic membrane transplantation, after strabismus surgery with adjustable sutures. In contrast, Escardo-Paton et $a l^{75}$ found that adjustable sutures did not alter the duration of conjunctival redness significantly. In our series, ${ }^{33}$ two patients $(1.7 \%)$ developed a suture granuloma or cyst, but the conjunctival hyperemia had disappeared by the 3 month postoperative visit in all cases.

Budning et $a l^{38}$ noted a slipped knot in one patient $(0.3 \%)$. In our series, the sliding noose slipped in one patient $(0.8 \%) .{ }^{29}$ Considering that no permanent knot will be tied to secure the muscle, we recommend tying the noose as tightly as possible when using the short tag noose or similar approaches and repeating the adjustment if a slipped noose is suspected.

\section{Future directions}

The postoperative healing process causes adhesions and inhibits delayed adjustment in patients with late postoperative drift. Efforts have been made to facilitate delayed adjustment by implanting physical barriers, such as silicone, viscoelastic material, absorbable adhesion barrier (Interceed TC7; Johnson and Johnson Medical Inc., Arlington, TX, USA), polyglactin 910 mesh, polytetrafluoroethylene (PTFE, WL Gore and Associates, Flagstaff, AZ, USA) or bioresorbable film (Surgiwrap, Macropore Biosurgery, San Diego, CA, USA), and antiproliferative agents such as mitomycin-C (all reviewed by Jee et $a l^{76}$ ). Choi et $a l^{77}$ were able to reduce postoperative adhesions following adjustable suture strabismus surgery in rabbits with the use of Adcon-L, a polyglycan ester in gelatin matrix that functions as a barrier to fibroblasts. The rabbit eyes showed less fibrosis on histologic evaluation for up to 3 weeks after surgery.

Polylactide-co-glycoside copolymer is one of the few biodegradable polymers that have been extensively studied and approved for human clinical use by Food and Drug Administration. It has been used for sitespecific controlled drug release over extended period in the eyes. ${ }^{78}$ Various drugs such as dexamethasone (antiinflammatory agent), ${ }^{76}$ Transilast (antiallergic drug), ${ }^{79}$ Paclitaxel (chemotherapeutic agent), ${ }^{80}$ and all-transretinoic-acid ${ }^{81}$ in PTFE/PGLA have been found to reduce adhesion and allowed delayed adjustment up to 5 weeks after surgery in rabbit eyes. Further studies are required to evaluate the effect and safety of various agents that might extend the period of postoperative adjustment in human eyes.

\section{Conclusion}

The fundamental deficit underlying many cases of strabismus is not the muscle itself but rather the central control of binocular alignment. If we could reprogram the brain to align the eyes, the success of surgery would be considerably higher. Unfortunately, no eye exercises, concentration techniques, or vision therapy can achieve such results. Lacking the ability to alter the central ocular motility control, we must resort to the inexact craft of eye muscle surgery, repositioning the muscles as the patient travels through life in the hope that, once the healing has subsided, the eyes will end up approximately aligned.

Once we recognize the difficulty of this task, it seems reasonable to do everything we can to further adjust and refine the eye position in the hours and days following strabismus surgery, including the use of adjustable sutures. However, adjustable sutures have not been universally accepted, partly because of insufficient evidence that the considerable extra investment of time and effort is worth the benefit, and partly because not all programs teach trainees the nuances of the approach. As a result, many strabismus surgeons do not perform adjustable suture surgery and become confident that there is no benefit. ${ }^{82}$ On the other hand, most published studies suggest that there is a benefit of suture adjustment, probably about a $10 \%$ improvement in success rates (Table 2).

Newer techniques are emerging that allow more time to elapse between the completion of primary surgery and suture adjustment. With the additional time to evaluate the results of primary surgery and perform modifications, it seems logical that the accuracy of surgery should improve. The use of adjustable suture strabismus surgery makes intellectual sense even in the 
absence of high-level evidence. ${ }^{83}$ Adjustable sutures do not guarantee excellent results, but they can be especially useful when more than usual uncertainty exists about the expected degree of correction, and all strabismus surgeons should be capable of offering this technique to their patients.

\section{Conflict of interest}

The authors declare no conflict of interest.

\section{Acknowledgements}

We thank Catharina Latz for translating Bielschowsky's article from the original German. We acknowledge Alison Clapp, our librarian at Children's Hospital Boston, for her extraordinary efforts in acquisition of articles. This study was supported in part by the Children's Hospital Ophthalmology Foundation, Boston, MA, USA.

\section{References}

1 Bielschowsky A. Die neueren Anschauungen über Wesen und Behandlung des Schielens. Med Klin 1907; iii: 335-336; translation by Catharina Latz, MD.

2 Jampolsky A. Strabismus reoperation techniques. Trans Sect Ophthalmol Am Acad Ophthalmol Otolaryngol 1975; 79: 704-717.

3 Jampolsky A. Current techniques of adjustable strabismus surgery. Am J Ophthalmol 1979; 88: 406-418.

4 Rosenbaum AL, Metz HS, Carlson M, Jampolsky AJ. Adjustable rectus muscle recession surgery: a followup study. Arch Ophthalmol 1977; 95: 817-820.

5 Keech RV, Scott WE, Christensen LE. Adjustable suture strabismus surgery. J Pediatr Ophthalmol Strabismus 1987; 24: 97-102.

6 Wisnicki HJ, Repka MX, Guyton DL. Reoperation rate in adjustable strabismus surgery. J Pediatr Ophthalmol Strabismus 1988; 25: 112-114.

7 Leuder GT, Scott WE, Kutschke PJ, Keech RV. Long term results of adjustable strabismus surgery for strabismus secondary to thyroid ophthalmopathy. Ophthalmology 1992; 99: 993-997.

8 Eino D, Kraft SP. Postoperative drifts after adjustable suture strabismus surgery. Can J Ophthalmol 1997; 32: 163-169.

9 Ogut MS, Onal S, Demirtas S. Adjustable suture surgery for correction of various types of strabismus. Ophthalmic Surg Lasers Imaging 2007; 38: 196-202.

10 Kraus DJ, Bullock JD. Treatment of thyroid ocular myopathy with adjustable and non-adjustable suture strabismus surgery. Trans Am Ophthalmol Soc 1993; 91: 67-79.

11 Tripathi A, Haslett R, Marsh IB. Strabismus surgery: adjustable sutures-good for all? Eye 2003; 17: 739-742.

12 Park YC, Chun BY, Kwon JY. Comparison of the stability of postoperative alignment in sensory exotropia: adjustable versus non-adjustable surgery. Korean J Ophthalmol 2009; 23: 277-280.
13 Bishop F, Doran RM. Adjustable and nonadjustable strabismus surgery: a retrospective case-matched study. Strabismus 2004; 12: 3-11.

14 George ND. Adjustable sutures: who needs them? Eye 2003; 17: 683-684.

15 Castelbuono AC, White JE, Guyton DL. The use of (a)symmetry of the rest position of the eyes under general anesthesia or sedation-hypnosis in the design of strabismus surgery: a favorable pilot study in 51 exotropia cases. Binocul Vis Strabismus Q 1999; 14: 285-290.

16 Mizrak A, Erbagci I, Arici T, Ozcan I, Ganidagli S, Tatar G. Ketamine versus propofol for strabismus surgery in children. Clin Ophthalmol 2010; 4: 673-679.

17 Haynes GR, Bailey MK. Postoperative nausea and vomiting: review and clinical approaches. South Med J 1996; 89: 940-949.

18 Pradda GS, Cruz OA, Krock JL. Comparison of postoperative emesis, recovery profile, and analgesia in pediatric strabismus repair. Rectal acetaminophen versus intravenous fentanyl-droperidol. Ophthalmology 1997; 104: 419-424.

19 Mendel HG, Guarnieri KM, Sundt LM, Torjman MC. The effects of ketorolac and fentanyl on postoperative vomiting and analgesic requirements in children undergoing strabismus surgery. Anesthesia \& Analgesia 1995; 80: 1129-1133.

20 Cogen MS, Guthrie ME, Vinik HR. The immediate postoperative adjustment of sutures in strabismus surgery with comaintenance of anesthesia using propofol and midazolam. J AAPOS 2002; 6: 241-245.

21 Ward JB, Niffenegger AS, Lavin CW, Acquadro MA, Ahern DK, Smith PV, McKeown CA. The use of propofol and mivacurium anesthetic technique for the immediate postoperative adjustment of sutures in strabismus surgery. Ophthalmology 1995; 102: 122-128.

22 Sanders RJ, Nelson LB, Deutsch JA. Peribulbar anesthesia for strabismus surgery. Am J Ophthalmol 1990; 109: 705-708.

23 Szmyd SM, Nelson LB, Calhoun JH, Harley RD. Retrobulbar anesthesia in strabismus surgery. Arch Ophthalmol 1984; 104: 1325-1327.

24 Brown DR, Pacheco EM, Repka MX. Recovery of extraocular muscle function after adjustable suture strabismus surgery under local anesthesia. J Pediatr Ophthalmol Strabismus 1992; 29: 16-20.

25 Snir M, Bachar M, Katz J, Friling R, Weinberger D, Axer-Siegel R. Combined propofol sedation with sub-tenon's lidocaine/marcaine infusion for strabismus surgery in adults. Eye 2007; 21: 1155-1161.

26 Guyton DL. Strabismus complications from local anesthetics. Semin Ophthalmol 2008; 23: 298-301.

27 Aziz ES, Rageh M. Deep topical fornix nerve block versus peribulbar block in one-step adjustable suture horizontal strabismus surgery. Br J Anaesth 2002; 88: 129-132.

28 Hakim OM, El-Hag YG, Hailkal MA. Strabismus surgery under augmented topical anesthesia. J AAPOS 2005; 9: 279-284.

29 Sami DA. Conjunctival incisions for strabismus surgery:a comparison of techniques. Techniq Ophthalmol 2007; 5: 125-129.

30 Wright KW, McVey JH. Conjunctival retraction suture for fornix strabismus adjustable surgery. Arch Ophthalmol 1991; 109: 138-141.

31 Spierer A. Adjustment of sutures 8 vs $24 \mathrm{~h}$ after strabismus surgery. Am J Ophthalmol 2000; 129: 521-524. 
32 Velez FG, Chan TK, Vives T, Chou T, Clark RA, Keyes M, Rosenbaum AL, Isenberg SJ. Timing of postoperative adjustment in adjustable suture strabismus surgery. I AAPOS 2001; 5: 178-183.

33 Nihalani BR, Whitman MC, Salgado CM, Loudon SE, Hunter DG. Short tag noose technique for optional and late suture adjustment in strabismus surgery. Arch Ophthalmol 2009; 127: 1584-1590.

34 Yi JH, Chung SA, Chang YH, Lee JB. Practical aspects and efficacy of intraoperative adjustment in concomitant horizontal strabismus surgery. J Pediatr Ophthalmol Strabismus 2010; 48(3): 85-89.

35 Bleik JH, Karam VY. Comparison of the immediate with the 24-h postoperative prism and cover measurements in adjustable muscle surgery: is immediate postoperative adjustment reliable? J AAPOS 2005; 8: 528-533.

36 Eustis HS, Elmer Jr TR, Ellis Jr G. Postoperative results of absorbable, subconjunctival adjustable sutures. J AAPOS 2004; 8: 240-242.

37 Robbins SL, Granet DB, Burns C, Freeman RS, Eustis HS, Yafai S, Cruz F, Danylyshyn-Adams K, Langham K. Delayed adjustable sutures: a multicentred clinical review. $\mathrm{Br} \mathrm{J}$ Ophthalmol 2010; 94: 1169-1173.

38 Budning AS, Day C, Nguyen A. The short adjustable suture Can J Ophthalmol 2010; 45: 359-362.

39 Haridas A, Sundaram V. Adjustable versus non-adjustable sutures for strabismus. Cochrane Database Syst Rev 2005; (1): CD004240; doi:10.1002/14651858.CD004240.pub2.

40 Saunders RA, O'Neill JW. Tying the knot: is it always necessary. Arch Ophthalmol 1992; 110: 1318-1321.

41 Kipioti A, George ND, Taylor RH. Tied and tidy: closing the conjunctiva over adjustable sutures. J Pediatr Ophthalmol Strabismus 2004; 41: 226-229.

42 Engel JM, Rousta ST. Adjustable sutures in children using a modified technique. J AAPOS 2004; 8: 243-248.

43 Nguyen DQ, Hale J, Von Lany H, Harrad RA. Releasable conjunctival suture for adjustable suture surgery. J Pediatr Ophthalmol Strabismus 2007; 44: 35-38.

44 Hakim OM, El-Hag YG, Haikal MA. Releasable adjustable suture technique for children. J AAPOS 2005; 9: 386-390.

45 Coats DK. Ripcord adjustable suture technique for use in strabismus surgery. Arch Ophthalmol 2001; 119: 1364-1367.

46 Chan TK, Rosenbaum AL, Hall L. The results of adjustable suture technique in paediatric strabismus surgery. Eye 1999; 13: $567-570$.

47 Dawson E, Bentley C, Lee J. Adjustable squint surgery in children. Strabismus 2001; 9: 221-224.

48 Awadein A, Sharma M, Bazemore MG, Saeed HA, Guyton DL. Adjustable suture strabismus surgery in infants and children. J AAPOS 2008; 12: 585-590.

49 Suh DW, Guyton DL, Hunter DG. An adjustable superior oblique tendon spacer with the use of nonabsorbable suture. J AAPOS 2001; 5: 164-171.

50 Jampolsky A. The Philip Knapp Lectureship [commentary] J AAPOS 1998; 2: 131-132.

51 Wright KW. Superior oblique silicone expander for Brown syndrome and superior oblique overaction. J Pediatr Ophthalmol Strabismus 1991; 28: 101-107.

52 Suh DW, Oystreck DT, Hunter DG. Long-term results of an intraoperative adjustable superior oblique tendon suture spacer using nonabsorbable suture for Brown syndrome. Ophthalmology 2008; 115: 1800-1804.
53 Thuangtong A, Isenberg SJ. Horizontal mattress technique for superior oblique suture spacer. J AAPOS 2009; 13: 422-423.

54 Goldenberg-Cohen N, Tarczy-Hornock K, Klink DF, Guyton DL. Postoperative adjustable surgery of the superior oblique tendon. Strabismus 2005; 13: 5-10.

55 Metz HS, Lerner H. The adjustable Harada-Ito procedure. Arch Ophthalmol 1981; 99: 624-626.

56 Nishimura JK, Rosenbaum AL. The long-term torsion effect of the adjustable Harada-Ito procedure. J AAPOS 2002; 6: 141-144.

57 Ameri A, Anvari F, Jafari AK, Ahadzadeghan I, Akbari MR, Rajabi MT. Intraoperative adjustable suture surgery for excyclotorsion: a modification of harada-ito procedure. J Pediatr Ophthalmol Strabismus 2009; 46: 368-371.

58 Kumar K, Prasad HN, Monga S, Bhola R. Hang-back recession of inferior oblique muscle in $\mathrm{V}$-pattern strabismus with inferior oblique overaction. J AAPOS 2008; 12: 401-404.

59 Scott AB. Posterior fixation: adjustable and without posterior sutures. In: Lennerstrand G (ed). Update on Strabismus and Pediatric Ophthalmology. CRC Press: Boca Raton, FL, 1994, pp 399-402.

60 Dawson E, Boyle N, Taherian K. Use of the combined recession and resection of a rectus muscle procedure in the management of incomitant strabismus. J AAPOS 2007; 11: 131-134.

61 Thacker NM, Velez FG, Rosenbaum AL. Combined adjustable rectus muscle resection-recession for incomitant strabismus. J AAPOS 2005; 9: 137-140.

62 Sarnicola V. The adjustable Faden operation: a new suggestion. AOJ 1992; 42: 26-29.

63 Holmes JM, Hatt SR, Leske DA. Lateral rectus posterior fixation suture. J AAPOS 2010; 14: 132-136.

64 Sprunger DT, Helveston EM. Progressive overcorrection after inferior rectus recession. J Pediatr Ophthalmol Strabismus 1993; 30: 145-148.

65 Wright KW. Late overcorrection after inferior rectus recession. Ophthalmology 1996; 103: 1503-1507.

66 Vazquez CW, Munoz M. Overcorrection after adjustable suture suspension-recession of the inferior rectus muscle in non-thyroid eye disease. Binocu Vis Strabismus Q 1999; 14: 103-106.

67 Kushner BJ. An evaluation of the semiadjustable suture strabismus surgical procedure. J AAPOS 2004; 8: 481-487.

68 Shokida MF, Gabriel J, Sanchez C. Safety stitch: a modification to postoperatively adjustable suture strabismus surgery of the inferior rectus muscle. Binocul Vis Strabismus Q 2007; 22: 210-215.

69 Kushner BJ. A surgical procedure to minimize lower-eyelid retraction with inferior rectus recession. Arch Ophthalmol 1992; 110: 1011-1014.

70 Pacheco EM, Guyton DL, Repka MX. Changes in eyelid position accompanying vertical rectus surgery and prevention of of lower lid retraction with adjustable surgery. J Pediatr Ophthalmal Surg 1992; 29: 265-272.

71 Isenberg SJ, Abdarbashi P. Drift of ocular alignment following strabismus surgery. Part 2: using adjustable sutures. Br J Ophthalmol 2009; 93: 443-447.

72 Hertle RW, Granet DB, Zylan S. The intraoperative oculocardiac reflex as a predictor of postoperative vaso-vagal responses during adjustable suture surgery. I Pediatr Ophthalmol Strabismus 1993; 30: 306-311.

73 Kushner BJ. Vagal responses to adjustable sutures in strabismus correction. Am J Ophthalmol 1993; 115: 124-126. 
74 Mocan MC, Azar NF. Amniotic membrane transplantation for the repair of severe conjunctival dehiscence after strabismus surgery with adjustable sutures. Am J Ophthalmol 2005; 140: 533-534.

75 Escardo-Paton JA, Harrad RA. Duration of conjunctival redness following adult strrbismus surgery. J AAPOS 2009; 13: $583-589$.

76 Jee JP, Choung HK, Kim CK, Hwang JM. Polytetrafluoroethylene/polylactide-co-glycolide laminate containing dexamethasone allows delayed adjustable strabismus surgery in a rabbit model. Invest Ophthalmol Vis Sci 2006; 47: 2485-2490.

77 Choi MY, Auh SJ, Choi DG, Chang BL. Effect of ADCON-L on adjustable strabismus surgery in rabbits. $\mathrm{Br} J$ Ophthalmol 2001; 85: 80-84.

78 Glordano GG, Arroyo MH, Retojo MF. Sustained delivery of retinoic acid from microspheres of biodegradable polymer in PVR. Invest Ophthalmol Vis Sci 1993; 34: 2743-2751.

79 Lee MJ, Jin SE, Kim CK, Choung HK, Jeoung JW, Kim HJ, Choe G, Hwang JM. Slow-releasing transilast in polytetrafluoroethylene/polylactide-co-glycolide laminate delays adjustment after strabismus surgery in rabbit model. Invest Ophthalmol Vis Sci 2007; 48: 699-704.

80 Choung HK, Jin SE, Lee MJ, Kim CK, Hwang JM. Slowreleasing paclitaxel in polytetrafluoroethylene/polylactideco-glycolide laminate delays adjustment after strabismus surgery in rabbit model. Invest Ophthalmol Vis Sci 2008; 49: 5340-5345.

81 Lee MJ, Jin SE, Kim CK, Choung HK, Kim HJ, Hwang JM. Effect of slow-releasing all-trans-retinoic-acid in bioabsorbable polymer on delayed adjustable strabismus surgery in a rabbit model. Am J Ophthalmol 2009; 148: 566-572.

82 Karmel M. Second chances: adjustable sutures for strabismus corrections. Eyenet 2010; 31-33.

83 Hunter DG. Do we need evidence for everything? Am Orthopt J 2010; 60: 59-62.

84 Hunter DG, Dingeman RS, Nihalani BR. Adjustable sutures in strabismus surgery. In: Wilson ME, Saunders RA, Trivedi RH (eds). Pediatric Ophthalmology: Current Thought and a Practical Guide. Springer: Heidelberg, Germany, 2008, pp 213-226. 